\title{
Acid Leaching-Based Synthesis of CdS Yellow Ceramic Pigment with Discarded Ni-Cd Batteries
}

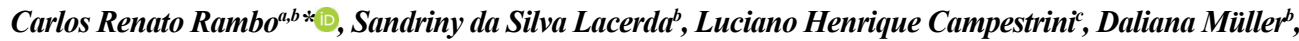 \\ Larissa da Silva Marques ${ }^{b}$, Dachamir Hotza ${ }^{d}$ (D) \\ ${ }^{a}$ Departamento de Engenharia Elétrica e Eletrônica, Universidade Federal de Santa Catarina, \\ Florianópolis, SC, Brasil \\ ${ }^{b}$ Laboratório de Materiais Elétricos, Departamento de Engenharia Elétrica e Eletrônica, \\ Universidade Federal de Santa Catarina, Florianópolis, SC, Brasil \\ cDepartamento de Bioquímica, Universidade Federal de Santa Catarina, Florianópolis, SC, Brasil \\ ${ }^{d}$ Departamento de Engenharia Química e Engenharia de Alimentos, Universidade Federal de Santa \\ Catarina, Florianópolis, SC, Brasil
}

Received: January 23, 2019; Revised: August 09, 2019; Accepted: August 21, 2019

\begin{abstract}
There is increasing interest in the ceramic industry in the development of pigments with intense tonalities that can be produced from low-cost alternative raw materials and also can fulfill technological and environmental requirements. This work reports on the preparation and characterization of $\mathrm{CdS}$ yellow ceramic pigment derived from $\mathrm{Ni}$-Cd batteries through an acid leaching process. Cadmium was chemically extracted with $\mathrm{HCl}$ and tributylphosphate (TBP) and reacted with $\mathrm{H}_{2} \mathrm{~S}$ to form $\mathrm{CdS}$. The obtained yellow powder is composed of agglomerated particles with nanometer sizes and hexagonal and rod-shaped crystals. Rietveld refinement indicated that these particles consist of cubic and hexagonal CdS. CIELab colorimetric parameters revealed a bright yellow color $\left(L^{*}=77.8, a^{*}=13.7\right.$ and $\left.b^{*}=76.2\right)$, similar to that of commercial Cd Yellow pigment. The extraction of $\mathrm{Cd}$ from Ni-Cd batteries could be a low-cost and environmentally friendly solution for the production of CdS-based ceramic pigments.
\end{abstract}

Keywords: $C d S$ yellow pigment, acid leaching, recycling of $\mathrm{Ni}$-Cd batteries.

\section{Introduction}

Ceramic pigments consist mostly of metallic oxides due to their high thermal and chemical stability. These pigments may contain heavy metals in their composition that result in differentiated colors. Some of the common urban toxic wastes, which have a disposal problem, are rich in metallic elements that can be used in other applications, such as in ceramic pigments. There is a growing interest from the ceramic industry in the development of pigments with intense tonalities from low-cost, alternative raw materials that can also meet their technological and environmental requirements. With new recycling methods, industrial residues and natural by-products have attracted great interest for the development of high added-value ceramic pigments ${ }^{1}$.

Cadmium sulfide is a semiconductor widely used in optoelectronics and chemical catalysis and it is also used in pigments in the arts and in the ceramic industry ${ }^{2-8}$. During the last few decades, many routes for the synthesis of this compound in the form of a powder, a single crystal, or a thin film have been reported, including microbial synthesis ${ }^{9-13}$. The high cost of Cd-based pigments has been linked to the price of the raw material (cadmium and selenium ores) and to the encapsulation process. The possible color pigments based on $\mathrm{Cd}$ range from yellow (CdS), through orange, to red-brown, gray and black (CdSe); all very intense. Thus, although they are expensive, these pigments are much desired by the ceramic industry.
The recycling of discarded electronic equipment and parts, such as batteries from cellphones that use $\mathrm{Cd}$ in their composition, offers a low-cost approach to the synthesis of $\mathrm{CdS}$ and other inorganic pigments. Cadmium is a carcinogenic heavy metal that is banned from being discarded as a conventional waste, which also motivates the development of new environmentally friendly recycling processes ${ }^{14}$. Almost $90 \%$ of the cadmium used worldwide is found in batteries and pigments, which motivates the recovery of $\mathrm{Cd}$ for further Cd-based pigment production.

The recycling of $\mathrm{Ni}-\mathrm{Cd}$ batteries has not always been economically favorable due to the constant fluctuation of the price of cadmium and the need for these batteries to be recycled independently of other battery types, at least in the processes that use distillation of metals. Thus, alternatives to recycling are still being studied, aiming to create new processes or to improve existing ones. The main methods of recycling batteries involve three distinct routes: i) Unity operations of mining treatment, where the components of batteries are physically separated for further recovering through other chemical processes; ii) Pyrometallurgical approach, where the components are distilled at high temperatures; and iii) Hydrometallurgical approach, through acid leaching of the metallic elements ${ }^{15}$. Nogueira et al ${ }^{16}$ applied the hydrometallurgical process for recovery of cadmium, cobalt and nickel from $\mathrm{Ni}-\mathrm{Cd}$ batteries. They reported a recovery of $99.7 \%$ of $\mathrm{Cd}$.

*e-mail: carlos.rambo@ufsc.br 
Through the data available from the hydrometallurgical route, it is known that for each ton of batteries it is possible to produce approximately $253 \mathrm{~kg}$ of $\mathrm{CdCl}_{2}$, yielding almost $200 \mathrm{~kg}$ of CdS ${ }^{17}$.

In this work, $\mathrm{Cd}$ from Ni-Cd batteries was chemically extracted by a hydrometallurgical process and used to synthesize a yellow inorganic, non-oxide CdS pigment.

\section{Experimental}

\subsection{Solubilization procedure}

Discharged Ni-Cd batteries from cellphones (around 10 per experiment) were manually disassembled and the internal content was carefully removed and submitted to an acid treatment with concentrated $\mathrm{HCl}(12 \mathrm{~mol} / \mathrm{L})$. Two main extractions were performed. In the first, the electrodes, the metal grid and the electrolytic paste were separated from de plastic and immersed into a flask containing the $\mathrm{HCl}$ solution. In the second, only the electrodes were treated with the $\mathrm{HCl}$ solution. The experiments were carried out under stirring on a hot plate at $40^{\circ} \mathrm{C}$ for 4 hours. The process was conducted under reflux in a hood. The ratio of material/ $\mathrm{HCl}$ was 150 g. $\mathrm{L}^{-1}{ }^{17}$. At the end of the procedure, the leached liquid was vacuum filtered and the residue was dried at $40^{\circ} \mathrm{C}$.

\subsection{Extraction procedure}

Tributylphosphate is a molecule of lower molar mass than those commonly used and has good extraction activity in metallic ions, as an additional extractor in solvation. Its main function is to form adducts with metallic complexes in the solution ${ }^{18}$. The equation for the extraction, using TBP, can be written as follows, where $\mathrm{MA}_{2}$, is salt of metal ${ }^{19}$.

$$
\mathrm{MA}_{2, \text { org }}+2 \mathrm{TBPorg}=\mathrm{MA}_{2, \text { org }}(\mathrm{TBP})_{2}
$$

The solute's cadmium was extracted with (TBP) dissolved in deodorized kerosene $(25 \% \mathrm{v} / \mathrm{v})$ over $5 \mathrm{~min}$. This process was repeated 3 times and the organic fractions containing $\mathrm{Cd}$ were collected. The $\mathrm{Cd}$ retained in the organic fractions was re-extracted with a $\mathrm{HCl}(6 \mathrm{~mol} / \mathrm{L})$ solution. The solution was then neutralized with $\mathrm{NaOH}(12 \mathrm{~mol} / \mathrm{L})$, which promoted the precipitation of $\mathrm{Cd}$ in $\mathrm{CdCl}_{2}{ }^{14}$.

In an aqueous solution, the following equation can be expressed:

$$
\begin{gathered}
\mathrm{Cd}(\mathrm{OH})^{2-}{ }_{(\text {aq })}+2 \mathrm{H}^{+}{ }_{\text {(aq) }}+\mathrm{TBP} \text { org } \\
\mathrm{CdCl}_{2} \cdot \text { TBPorg }+2 \mathrm{H}_{2} \mathrm{O}
\end{gathered}
$$

In the presence of $\mathrm{NaOH}$ in the solution, $\mathrm{CdCl}_{2}$ is then precipitated from the complex formed in Eq. (2). Studies of the effect of multiples ions in the extraction in strong acid solution, using hydrochloric acid media in the extraction of cadmium and TBP as organic phase to obtain a complex TBP-Cd, reported evidences of the species $\mathrm{MCl}_{2}$ 2TBP ${ }^{20}$.
Further studies have revealed the formation of coordinate complex between $\mathrm{CdCl}_{2}$ and solvent and the presence of other metal species may induce the formation of $\mathrm{MCl}_{3}{ }^{-}$complexes and $\mathrm{MCl}_{4}{ }^{-}$complexes, according to the reaction ${ }^{21}$ :

$$
2 \mathrm{CdCl}_{2} \leftrightarrow \mathrm{CdCl}^{+}+\mathrm{CdCl}_{3}^{-}
$$

The resulted powder was separated from the solution by centrifugation and washed with distilled water to remove residual salts and impurities. After drying, the precipitated $\mathrm{Cd}$ was reacted with $\mathrm{H}_{2} \mathrm{~S}$ in a concentrated solution to form $\mathrm{CdS}$. The $\mathrm{CdS}$ produced after the first and second extractions were labeled as CdS- 1 and CdS2 , respectively.

The phase composition of the obtained powders were analyzed by X-ray diffractometry at room temperature using a Philips diffractometer model $\mathrm{X}$ 'Pert with $\mathrm{CuK} \alpha$ radiation $(\lambda=1.54 \AA)$ and scan rate of $1 \%$ min over a $2 \theta$ interval between $10^{\circ}$ and $90^{\circ}$. Quantitative analysis of the XRD patterns was carried out through Rietveld refinement method, using the software GSAS ${ }^{22}$. The microstructure was evaluated by transmission electron microscopy (TEM, JEOL-JEM 1011) with a maximum acceleration voltage of $80 \mathrm{kV}$ and scanning electron microscopy (SEM, JEOL JSM-6390LV) combined with energy dispersive X-ray spectroscopy (EDS) for elemental analysis operating at different accelerating voltages. For SEM observations, the powder was deposited on aluminum stubs and coated with gold. For TEM analysis, the powder was dispersed in ethanol and dispersed over a carbon grid. The color parameters $\mathrm{L}^{*}, \mathrm{a}^{*}$ and $\mathrm{b}^{*}$ of the powder were determined using the computer vision system (CVS) ${ }^{23,24}$. Images were taken from a camera (Nikon D5500, Nikon Corporation, Japan) and treated by the software ImageJ v. 1.6.0 (NIH, USA) to convert RBG color system to CIELab scale. Measurements were performed in triplicate.

\section{Results and Discussion}

After the first extraction, the precipitate from the leach exhibited a brownish color, indicating that it is not pure cadmium chloride (which is white). After the reaction with sulfur, a yellow-dark complexion was formed, indicating that, if CdS formation had occurred, it was incomplete or associated with other compounds. The interval between leaching and TBP extraction plays a key role in Cd extraction. The first extraction was performed using a $48 \mathrm{~h}$ interval. During the time the solution being held, the leaching reaction continued and this may have altered the final composition of the filtrate. On the other hand, the brown color of the precipitate indicates the possible presence of iron $\left(\mathrm{Fe}_{2} \mathrm{O}_{3}\right)$. Therefore, we suggest that the leaching of the metal grid releases Fe ions into the solution and this occurs throughout the extraction process until neutralization and precipitation. 
Figure 1 shows the spectra of EDS from the CdS produced after the first extraction (Fig. 1a) and the CdS obtained after the second extraction (Fig. 1b).

The suspected contamination with iron (III) oxide was confirmed by the presence of a characteristic peak of Fe. It was therefore concluded that the metal grid is the source of the iron impurity. Cobalt peaks were also identified, which are consistent with the battery composition since it also contains cobalt in the cathode to increase the performance of the battery. The second extraction started from the pure electrode and, therefore, Fe-based impurities would not be expected (Fig. 1b).

Fig. 2 shows the X-ray diffraction spectra of the products of the reactions between $\mathrm{H}_{2} \mathrm{~S}$ and $\mathrm{CdCl}_{2}$ as compared with reference samples.

Both $\mathrm{Cd}$ and $\mathrm{CdCl}_{2}$ reacts with the $\mathrm{H}_{2} \mathrm{~S}$ to form the desired yellow colored cadmium sulfide according to the following reactions:

$$
\begin{gathered}
\mathrm{Cd}(\mathrm{s})+\mathrm{H}_{2} \mathrm{~S}(\mathrm{~g}) \rightarrow \mathrm{CdS}(\mathrm{s})+\mathrm{H}_{2}(\mathrm{~g}) \\
\mathrm{CdCl}_{2}(\mathrm{aq})+\mathrm{H}_{2} \mathrm{~S}(\mathrm{~g}) \rightarrow \mathrm{CdS}(\mathrm{s})+2 \mathrm{HCl}(\mathrm{aq})
\end{gathered}
$$

Cadmium sulfide is present in all spectra of samples after first and second extraction. Although $\mathrm{Fe}, \mathrm{Ni}$ and $\mathrm{Co}$ was detected in EDS analysis, it could not be detected in XRD, due to the technique resolution. The broad peaks of the samples revealed that the CdS is nanocrystalline with a significant amorphous phase, when compared to the sharp peaks of the commercial pigment. All CdS peaks were indexed after ICSD files. After the first extraction procedure, not only pure cadmium was removed and some non-reacted specimens could be present. Despite CdS crystalline phases (cubic and hexagonal), cadmium chloride $\left(\mathrm{CdCl}_{2}\right)$, cadmium perchlorate $\left(\mathrm{CdCl}_{2} \mathrm{O}_{8}\right)$ and cadmium hydroxide $\left(\mathrm{Cd}(\mathrm{OH})_{2}\right)$ could be indexed as well. The intensity of the diffraction peaks of the CdS-1 powder was too low for a reliable quantitative crystalline phase analysis.
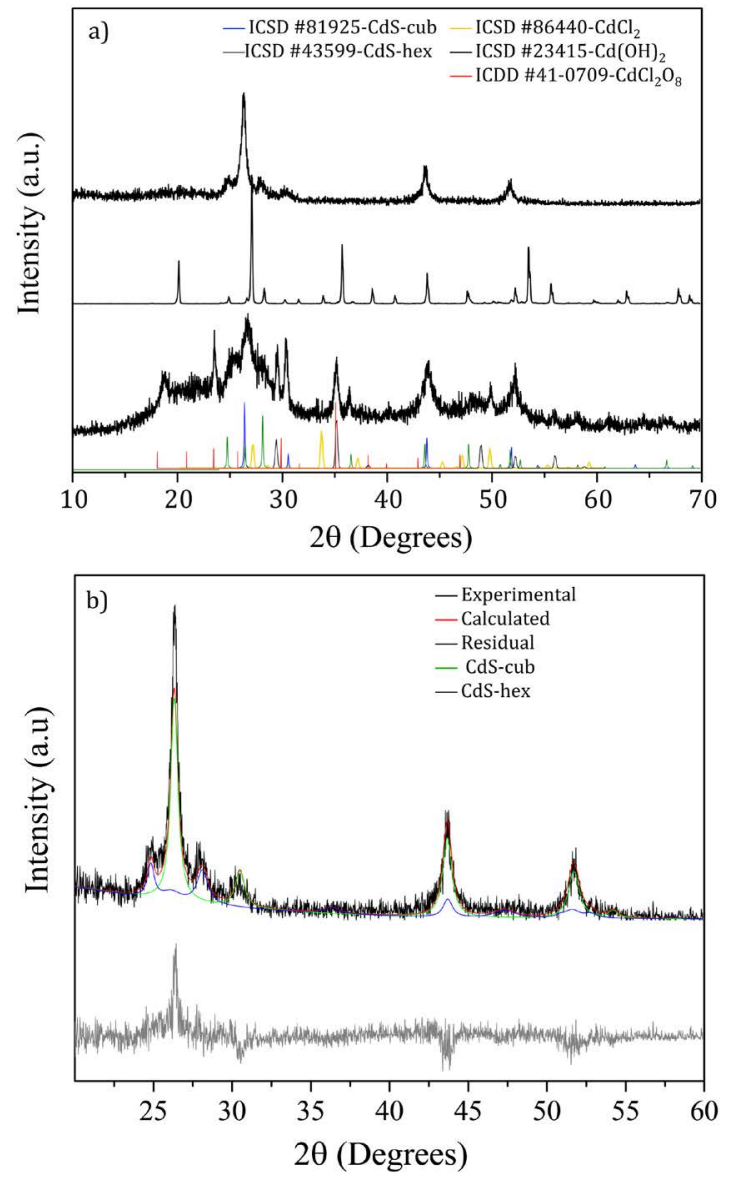

Figure 2. a) X-ray diffraction spectra of the products obtained after both of extraction processes. The spectrum of commercial CdS powder is also shown. b) Rietveld refinement of CdS-2.

Nevertheless, Rietveld refinement revealed that the amorphous phase represents approximately $65 \%$ in this sample. Rietveld refinement on the CdS sample produced after the second extraction (Fig. 2b) returned two polymorphic phases of cadmium sulfide: cubic CdS, ICSD \#81925 (majority phase, 69\%)
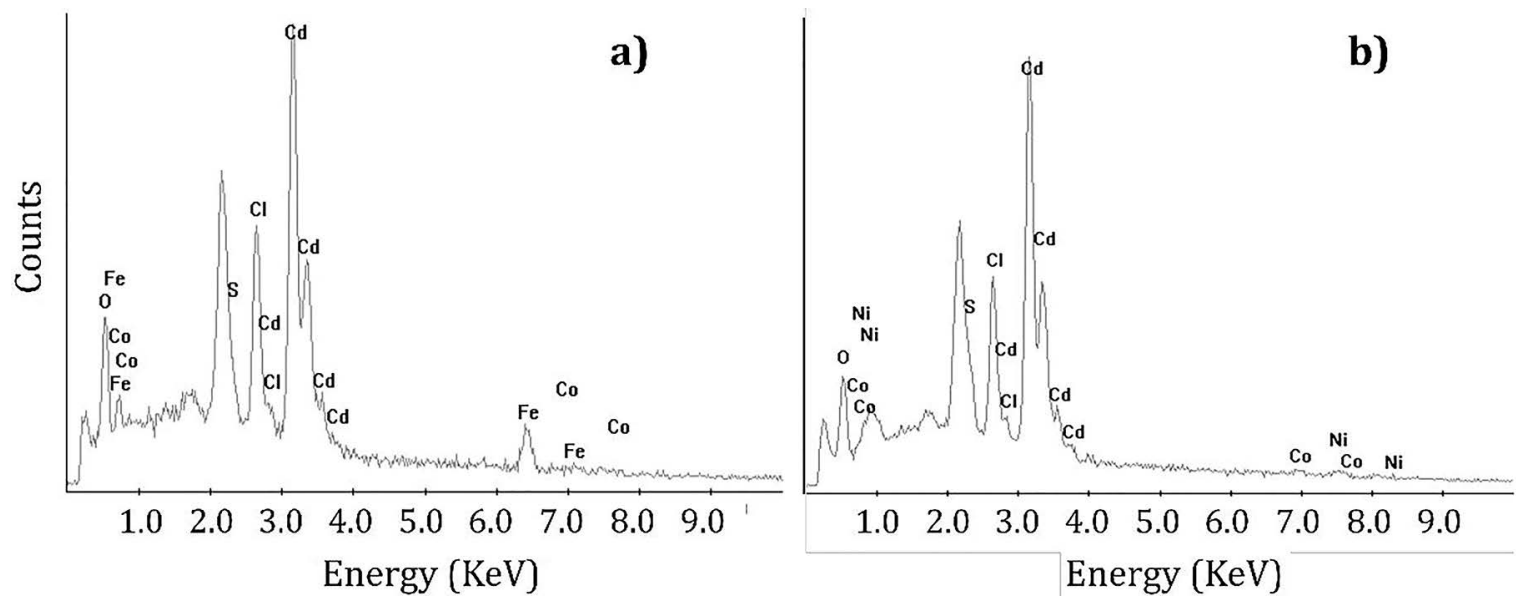

Figure 1. EDS spectra of: a) CdS from the first extraction process; b) CdS produced from reaction between the obtained from the second extraction. 
and hexagonal CdS, ICSD \#43599 (31\%). In the second extraction procedure only the $\mathrm{Cd}$-containg electrode was used for cadmium extraction and, therefore, a more pure substrate for producing $\mathrm{CdS}$.

Fig. 3 shows an SEM micrograph of the CdS powder obtained after the second extraction (Fig. 3a and b) and an EDS analysis (Fig. 3c and d) of the highlighted region in Fig. 3b. Fig. 3d shows a bright field TEM image of the synthesized CdS powder.

The analysis of the microstructure of the sample (Fig. 3a and b) revealed that the powder after reaction of $\mathrm{CdCl}_{2}$ with $\mathrm{H}_{2} \mathrm{~S}$ was composed of particles with sizes ranging from the submicron scale to large agglomerates (larger than $10 \mu \mathrm{m}$ ). To confirm the previous hypothesis that CdS was formed on the surface of precipitated Cdbased salt, two different beam acceleration voltages were used to analyze the elemental composition of particle's inner (at $30 \mathrm{kV}$, Fig. 3c) and surface (at $15 \mathrm{kV}$, Fig. 3d) composition highlighted in Fig. 3b. Both on the surface and in the interior $\mathrm{Cd}$ and $\mathrm{S}$ appeared as major elements.
Although $\mathrm{Cl}$ is detected only in the inner part of the agglomerate, which could confirm that the reaction occurred only on the surface, its amount is too low (1.4 wt.\%) to be considered as significant. TEM analysis (Fig. 3e) revealed that, as confirmed by XRD analysis, submicrometer (mostly below $200 \mathrm{~nm}$ ) sized hexagonal platelets are surrounded by nanosized CdS particles. Nanoparticles with sizes of few nanometers (below $20 \mathrm{~nm}$ ) are distributed over the large crystals, which indicates that the reaction to form $\mathrm{CdS}$ resulted in different shaped crystals. A cluster of nanoparticles is displayed at the bottom-left region of the micrograph, while at the top-right few hexagonal crystals can be observed.

Fig. 4 shows a photograph of the resulting powder (left) together with a CIELab chart (right).

The CdS powder obtained after the second extraction is characterized by CIELab coordinates of $\mathrm{L}^{*}=77.8 \pm 0.4$, $b^{*}=76.2 \pm 0.2$ and $a^{*}=13.7 \pm 1.1$, where $L^{*}$ represents brightness, $b^{*}$ represents yellow value and $a^{*}$ represents red value. High $\mathrm{L}$ value, high $b^{*}$ value and low $a^{*}$ value indicate the synthesized CdS powder shows a bright yellow color, which is comparable to that of commercial Cd-based yellow pigments.
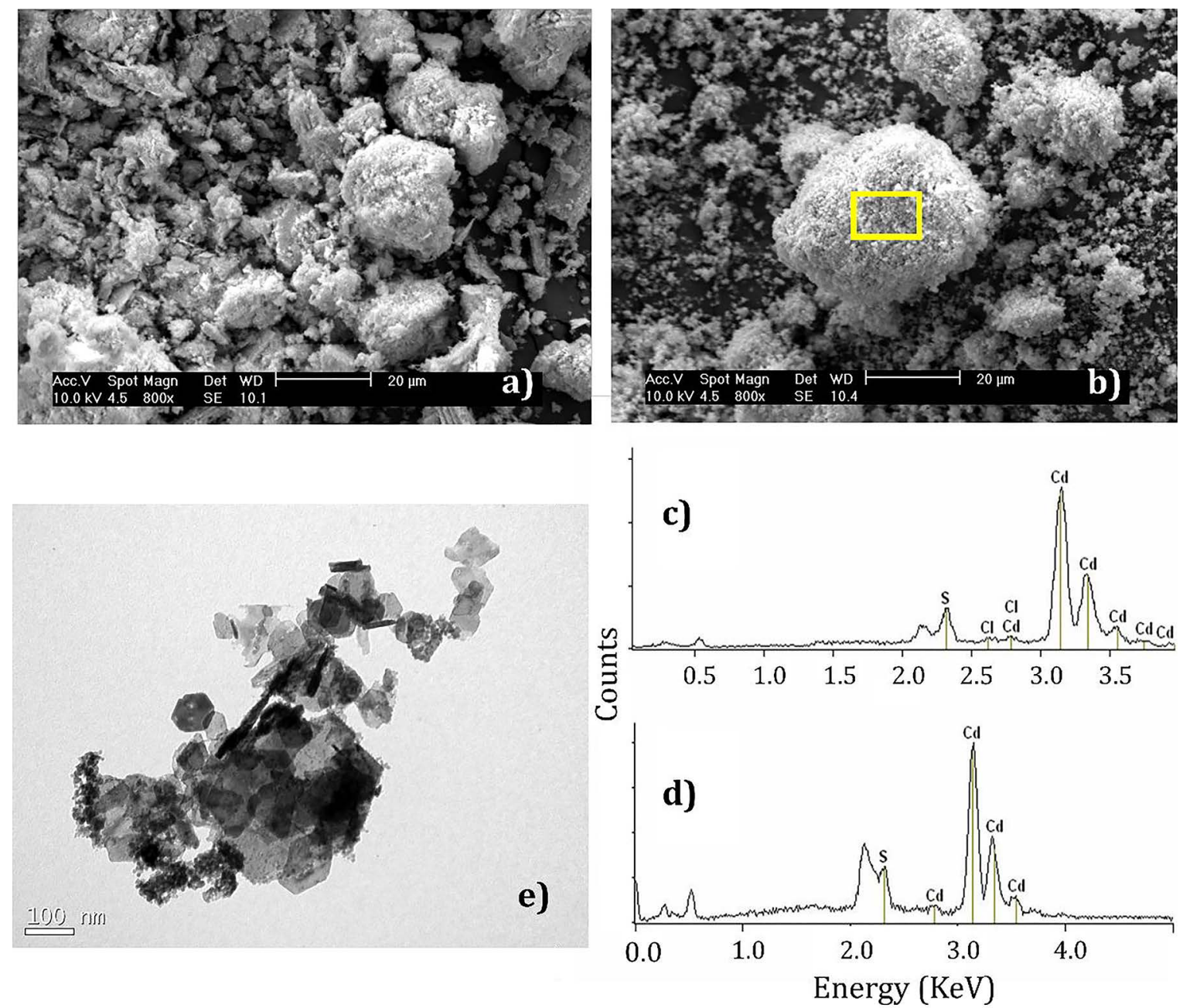

Figure 3. a), b) SEM.micrographs of the CdS-2 powder; c) EDS spectrum of the region highlihghted in b) at $30 \mathrm{kV}$; d) EDS spectrum of the region highlihghted in b) at $15 \mathrm{kV}$; e) Bright field TEM image of the synthesized CdS-2 powder. 


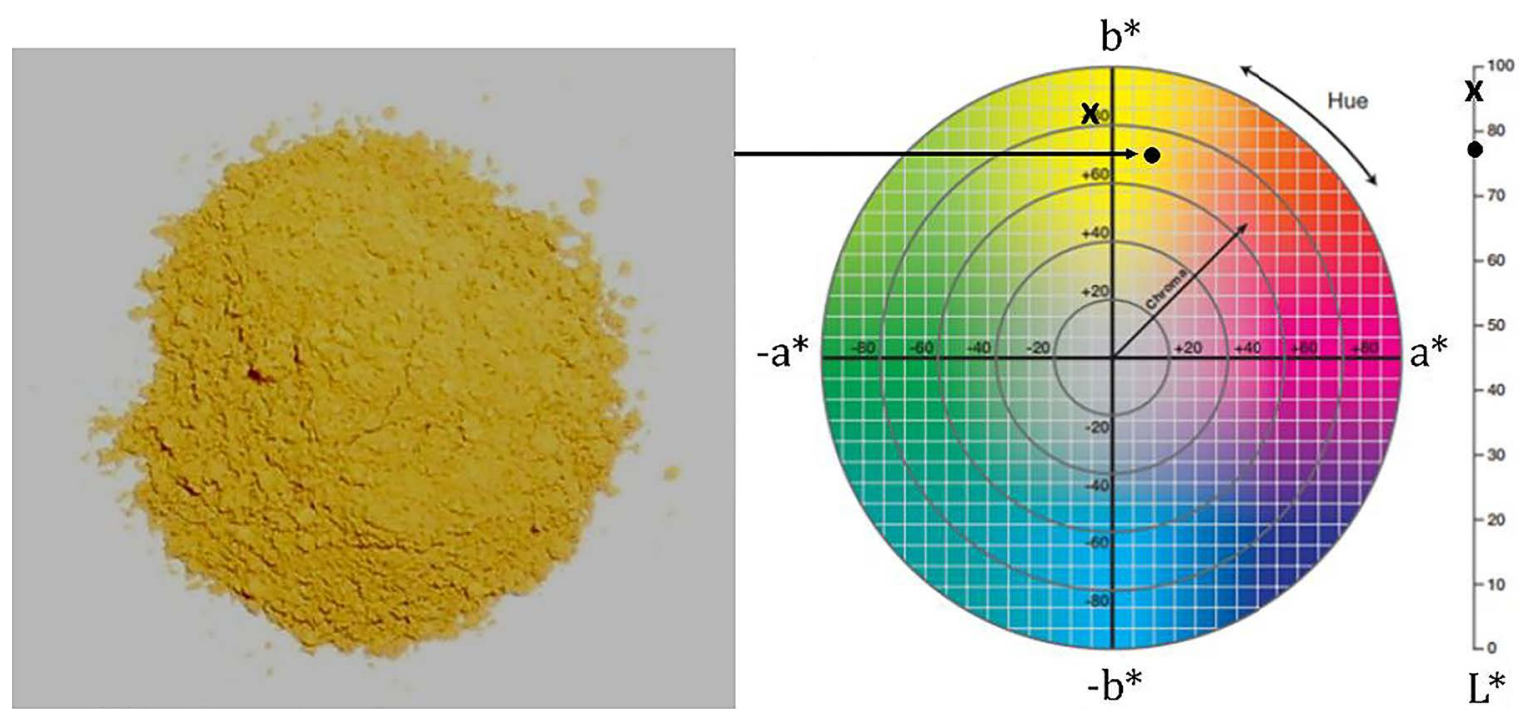

Figure 4. Photograph of the obtained powder (left) and CIELab chart (right) showing the color coordinates of the synthesized CdS-based pigment $(\bullet)$ compared to a commercial Cd-based yellow pigment $(\mathbf{x})$.

The extraction of Cd from Ni-Cd batteries could be a lowcost and environmental solution for production of CdS-based pigments, considering the well-established hydrometallurgical process in the industry. The battery recycling process can reach up to $20 \%$ efficiency conversion into CdS per ton of batteries processed, if $100 \%$ of the byproduct, $\mathrm{CdCl}_{2}$, reacts to form CdS.

\section{Conclusion}

CdS-based yellow ceramic pigments were synthesized from cadmium extracted from discarded $\mathrm{Ni}-\mathrm{Cd}$ batteries. An acid leaching process with $\mathrm{HCl}$ was applied to capture the $\mathrm{Cd}$, resulting in $\mathrm{CdCl}_{2}$, which further reacted with gaseous $\mathrm{H}_{2} \mathrm{~S}$ to form CdS. The obtained yellow powder is composed of agglomerated particles with nanometer sizes and hexagonal and rod-shaped crystals. Rietveld refinement indicated that these particles consist of cubic and hexagonal CdS. CIELab colorimetric parameters revealed a bright yellow color, similar to that of commercial cadmium Yellow pigment.

\section{Acknowledgements}

The authors would like to thank the National Council for Scientific and Technological Development (CNPq/Brazil) for financial support and Coordination for the Improvement of Higher Level Personnel (CAPES/Brazil) for the scholarships. The authors thank Dr. Jaqueline de Oliveira Moraes for colorimetric measurements at LATESC-UFSC. The authors also thank the Central Laboratory of Electronic Microscopy (LCME at UFSC). The following laboratories at UFSC are also acknowledged: LDRX, CERMAT and LAMATE.

\section{References}

1. Costa G, Della VP, Ribeiro MJ, Oliveira APN, Monrós G, Labrincha JA. Synthesis of black ceramic pigments from secondary raw materials. Dyes and Pigments. 2008;77(1):137-144.

2. Shubenkova EG and Veprikova YR. Structural and electronic properties of cadmium sulfide nanoparticles synthesized in inverse emulsion AOT. Dynamics of Systems, Mechanisms and Machines. 2016;1-3.

3. Zhao Y, Yuan M, Chen Y, Huang Y, Lian J, Cao S, Li H, Wu L. Size controllable preparation of sphere-based monolayer CdS thin films for white-light photodetectors. Ceramics International. 2018;44:2407-2412.

4. Sanjay RD, Henry AC, Hong TH. Photoluminescence properties of thermally stable highly crystalline CdS nanoparticles. Materials Research. 2013;16(2):504-507.

5. Mass JL, Opila R, Buckley B, Cotte M, Church J, Mehta A. The photodegradation of cadmium yellow paints in Henri Matisse's Le Bonheur de vivre (1905-1906). Applied Physics A. 2013;111(1):59-68.

6. Eroles AJ, Friedberg AL. Color and structural character of CdSCdSe pigments. Journal of the American Ceramic Society. 1965;48(5):223-227.

7. Van der Snickt G, Dik J, Cotte M, Janssens K, Jaroszewicz J, De Nolf W, Groenewegen J, Van der Loeff L. Characterization of a degraded cadmium yellow (CdS) pigment in an oil painting by means of synchrotron radiation based X-ray techniques. Analytical Chemistry. 2009;81(7):2600-2610.

8. Giacopetti L, Satta A. Degradation of Cd-yellow Paints: ab initio study of the adsorption of oxygen and water on $\{10.0\} \mathrm{CdS}$ surface. Journal of Physics: Conference Series. 2014;566:012021. 
9. Li YD, Liao HW, Ding Y, Qian YT, Yang L, Zhou GE. Nonaqueous synthesis of CdS nanorod semiconductor. Chemistry of Materials. 1998;10(9):2301-2303.

10. Trindade T, O'Brien P, Zhang XM. Synthesis of CdS and CdSe nanocrystallites using a novel single-molecule precursors approach. Chemistry of Materials. 1997:9:523-530.

11. Ortuño-López MB, Ochoa-Landín R, Sandoval-Paz MG, Sotelo-Lerma M, Flores-Acosta M, Ramírez-Bon R. Studies on the properties of CdS films deposited from $\mathrm{pH}$-controlled growth solutions. Materials Research. 2013;16(4):937-943.

12. Ahmad A, Mukherjee P, Mandal D, Senapati S, Khan MI, Kumar R, Sastry M. Enzyme Mediated Extracellular Synthesis of CdS nanoparticles by the fungus, Fusarium oxysporum. Journal of the American Chemical Society. 2002;124(41):12108-12109.

13. Kowshik M, Deshmukh N, Vogel W, Urban J, Kulkarni SK, Paknikar KM. Microbial synthesis of semiconductor CdS nanoparticles, their characterization, and their use in the fabrication of an ideal diode. Biotechnology and Bioengeneering. 2002;78(5):583-588.

14. Wilburn DR. Material Use in the United States - Selected case studies for Cadmium, Cobalt, Lithium, and Nickel in rechargeable batteries. Geological Survey Scientific Investigations Report. 2008:5141-5160.

15. Espinosa DCR, Bernardes AM, Tenório JAS. An overview on the current processes for the recycling of batteries. Journal of Power Sources. 2004;135(1-2):311-319.

16. Nogueira CA, Delmas F. New flowsheet for the recovery of cadmium, cobalt and nickel from spent $\mathrm{Ni}-\mathrm{Cd}$ batteries by solvent extraction. Hydrometallurgy. 1999;52(3):267-287.
17. Barandas A, Valverde Junior IM, Afonso JC, Mantovano JL, Cunha JWSD. Recovery of cadmium from nickel-cadmium batteries via selective extraction with tributylphosphate (TBP). Química Nova. 2007;30(3):712-717.

18. Rydberg J, Cox M, Musikas C, Chopping GR. Solvent Extraction Principles and Practise. $2^{\text {nd }}$ ed. New York: Marcel Dekker, Inc.; 2004.

19. Gajda B, Bogacki MB. The effect of tributyl phosphate on the extraction of nickel(II) and cobalt(II) ions with di(2-ethylhexyl) phosphoric acid. Physicochemical Problems of Mineral Processing. 2007;41(1):145-152.

20. Sato T. The extraction of divalent cobalt, copper, zinc and cadmium from hydrochloric acid solutions by tri-n-butyl phosphate. Journal of Applied Chemistry and Biotechnology. 1972;22(12):1233-1242.

21. Waters DN, Short EL, Tharwat M, Morris DFC. Vibrational spectra of some halide complexes of zinc(II), cadmium(II), and mercury(II) in solution in tri-n-butyl phosphate. Journal of Molecular Structure. 1973;17(2):389-400.

22. Larson AC, Von Dreele RB. GSAS-General Structure Analysis System. LAUR 86-748. Los Alamos, NM: Los Alamos National Laboratory; 1985-2004. Available from: http://www.ccp14. ac.uk/solutions/gsas

23. Cárdenas-Pérez S, Chanona-Pérez J, Méndez-Méndez JV, Calderón-Domínguez G, López-Santiago R, Perea-Flores MJ, Arzate-Vázquez I. Evaluation of the ripening stages of apple (Golden Delicious) by means of computer vision system. Biosystems Engineering. 2017;159:46-58.

24. Simão RS, Moraes JO, Souza PG, Carciofi BAM, Laurindo JB. Production of mango leathers by cast-tape drying: Product characteristics and sensory evaluation. LWT. 2019;99:445-452. 